Simon Finfer

V. Marco Ranieri

B. Taylor Thompson

Philip S. Barie

Jean-François Dhainaut

Ivor S. Douglas

Bengt Gårdlund

John C. Marshall

Andrew Rhodes

\section{The PROWESS SHOCK trial: reply to Paramesh et al.}

Accepted: 4 December 2008

Published online: 9 January 2009

(C) Springer-Verlag 2008

This reply refers to the comment available at: doi:10.1007/s00134-008-1389-9.

Dear editor,

Drs. Paramesh and Zwaal suggest that any trial of activated protein $\mathrm{C}$ should be conducted independently of the drug manufacturer or anyone with financial links to the manufacturer, and without the involvement of anyone previously involved in trials of activated protein $C$ [1]. This suggestion has great merit and we encourage Drs. Paramesh and Zwaal to conduct that trial. In the meantime, the academic members of the steering committee have joined with Lilly to conduct the PROWESS SHOCK trial and to build into that trial as many safeguards as possible; these include giving the academics control over the interpretation and publication of the data and providing the academics with an absolute right to communicate publicly about the conduct of the trial. Additionally, we are pleased to announce that Robert M. Califf M.D., Kerry Lee Ph.D. and colleagues at the Duke Clinical Research Center will serve as the Academic Statistical Center for the trial.

Until trials such as PROWESS SHOCK can be funded and conducted by independent organisations we believe it is in the best interest of the medical community and our patients to work with industry to conduct the most methodologically rigorous and transparent trials possible, to conduct independent analysis and interpretation of the data and have the study publications written by academics rather than by industry. These processes are in place for the PROWESS SHOCK trial.

\section{Reference}

1. Paramesh KS, Zwaal J (2009) Prolonging resuscitation \& postponing the death of activated protein $\mathrm{C}$ or is it? Intensive Care Med. doi:10.1007/s00134-008$1389-9$

\section{S. Finfer ( )}

The George Institute for International

Health, University of Sydney, Sydney, Australia

e-mail: sfinfer@george.org.au
V. Marco Ranieri

Ospedale S. Giovanni Battista-Molinette, Università di Torino, Torino, Italy

B. Taylor Thompson

Pulmonary and Critical Care Unit, Massachusetts General Hospital, Bullfinch Building, Room 148, 55 Fruit Street,

Boston, MA 02114, USA

P. S. Barie

Department of Surgery, P713A,

Weill Cornell Medical College,

525 East $68 \mathrm{St}$,

New York, NY 10065, USA

J.-F. Dhainaut

Cochin Port Royal Hospital, Paris Descartes University, Paris, France

\section{S. Douglas}

Denver Health and University of Colorado, Denver, USA

\section{B. Gårdlund}

Department of Infectious Diseases,

Karolinska University Hospital,

14186 Stockholm, Sweden

J. C. Marshall

Departments of Surgery and Critical Care Medicine, St. Michael's Hospital, 4th Floor Bond Wing, Rm. 4-007, 30 Bond Street,

Toronto, ON M5B 1W8, Canada

A. Rhodes

Consultant in Intensive Care Medicine and Anaesthesia, St George's Hospital, London SW17 0QT, UK 